\title{
Autism, imprinting and epigenetic disorders: a metabolic syndrome linked to anomalies in homocysteine recycling starting in early life??
}

\author{
Yves Ménézo • Pierre Mares • Marc Cohen • \\ Michel Brack • Stephane Viville $\cdot$ Kay Elder
}

Published online: 3 November 2011

(C) Springer Science+Business Media, LLC 2011

An association between imprinting syndromes and ART is now common knowledge. Imprinting problems are roughly linked to DNA methylation disorders, and clinical

Capsule Monitoring and early supplementation with parameters linked to homocysteine metabolism immediately before and during pregnancy, as well as during early infancy of the child, could limit the risks of developing autism spectrum and imprinting related disorders.

Yves Ménézo, Marc Cohen and Michel Brack are members of the oxidative stress College, Paris

\section{Y. Ménézo}

UNILABS Clinique du Cotentin,

50120 Equeurdreville et 55 rue St Didier,

75116 Paris, France

\section{P. Mares}

Department of gynecology and Obstetrics,

G.H.U. Caremeau,

30029 Nimes, France

Y. Ménézo • M. Cohen

Procrelys, Maison médicale Ambroise Paré,

28 avenue Rockefeller,

69008 Lyon, France

\section{Brack}

Clinique Alleray Labrousse,

Université Pierre et Marie Curie,

75013 Paris, France

\section{S. Viville}

Institut de Génétique et de Biologie Moléculaire et Cellulaire (IGBMC), Institut National de Santé et de Recherche Médicale (INSERM) U964/Centre National de Recherche Scientifique (CNRS) UMR 1704/Université de Strasbourg,

67404 Illkirch, France

\section{K. Elder $(\bowtie)$}

Bourn Hall Clinic Bourn, Cambridge CB23 2TN, UK

e-mail: kay.elder@gmail.com reports of ART-linked imprinting syndromes have implicated hypomethylation of the maternal alleles (1). Kattari et al. (2), examining DNA methylation in 700 genes, observed different levels of methylation between children conceived in vitro and in vivo. They also found that the differences observed in DNA methylation in the children conceived in vitro involved differences in gene expression for both imprinted and non-imprinted genes. This effect is observed even when maternal age is taken into account. We recently pointed out some aspects of in vitro and in vivo parameters that could be responsible for impairment of methylation processes in ART patients (3), in particular an increased concentration of homocysteine (Hcy) in the oocyte environment.

Further to these observations, two articles recently presented at the International meeting for autism research in Philadelphia pointed out a correlation between Assisted Reproductive Technology and Autism. 111 women who had a child with an autism spectrum disorder (ASD) took part in the Nurses' Health Study II, which revealed that about $4 \%$ of mothers who took fertility drugs had a child with an ASD, compared to about $2 \%$ who did not take fertility drugs. In a second study, an Israeli group also observed an increased frequency in babies with ASD after ART: 10.5\% of 461 children diagnosed with a disorder on the autism spectrum were conceived using IVF, significantly higher than the $3.5 \%$ autism rate in the general Israeli population. Two major metabolic problems are commonly involved in Autism disorders: altered thiol metabolism and increased homocysteine levels, and oxidative stress including mitochondrial dysfunction (4-8) In many cases a correlation is found with alterations in the mothers of autistic children $(9,10)$.

One mechanism that oxidative stress/thiol metabolism and methylation (imprinting) have in common is the recycling of homocysteine (see Fig. 1). Recycling of homocysteine is a 
Fig. 1 Homocysteine involvement in oxidative stress and DNA-linked cellular dysfunction. Vitamin and co-factor deficiencies can lead to an increase in homocysteine levels, which result in decreased (-) levels of uracil and decreased $(-)$ methylation. These metabolic disruptions, along with unrepaired DNA

fragmentation, can influence imprinting mechanisms and cause genetic instability

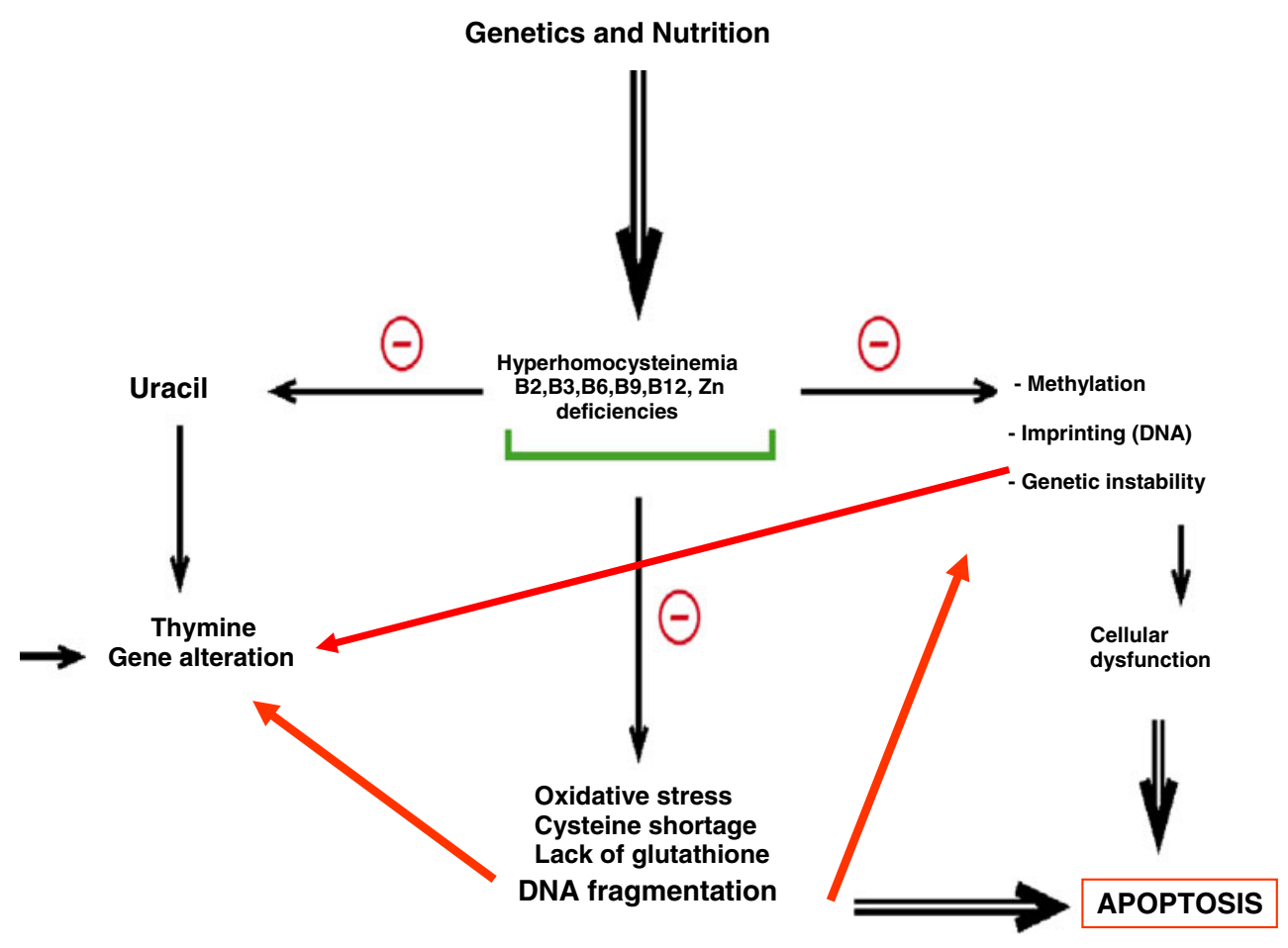

complex process involving 3 pathways that require numerous cofactors, especially Zinc and vitamins of the B group (Fig. 2). Homocysteine also competes with methionine for uptake into the embryo (11), and this hinders the formation of S-Adenosyl methionine, the universal methylation agent. The most important pathway for Hcy recycling is the folate pathway, which requires vitamins B3, B9 (folic acid) and B12. The second Hcy recycling mechanism is the cystathionine beta synthase pathway (CBS), requiring vitamin B6, which leads to the formation of cysteine (and then glutathione). Glutathione is the universal natural (endogenous) protector against DNA decays caused by oxidative stress. A third pathway is Betaine-homocysteine methyl transferase (BHMT), which is usually weakly represented in tissues other than the liver.

In contrast to what is observed in the mouse, human oocytes and early embryos do not express the CBS pathway, and expression of BHMT is extremely weak. In
Fig. 2 Homocysteine recycling: involvement of $\mathrm{Zn}$ and group B vitamins

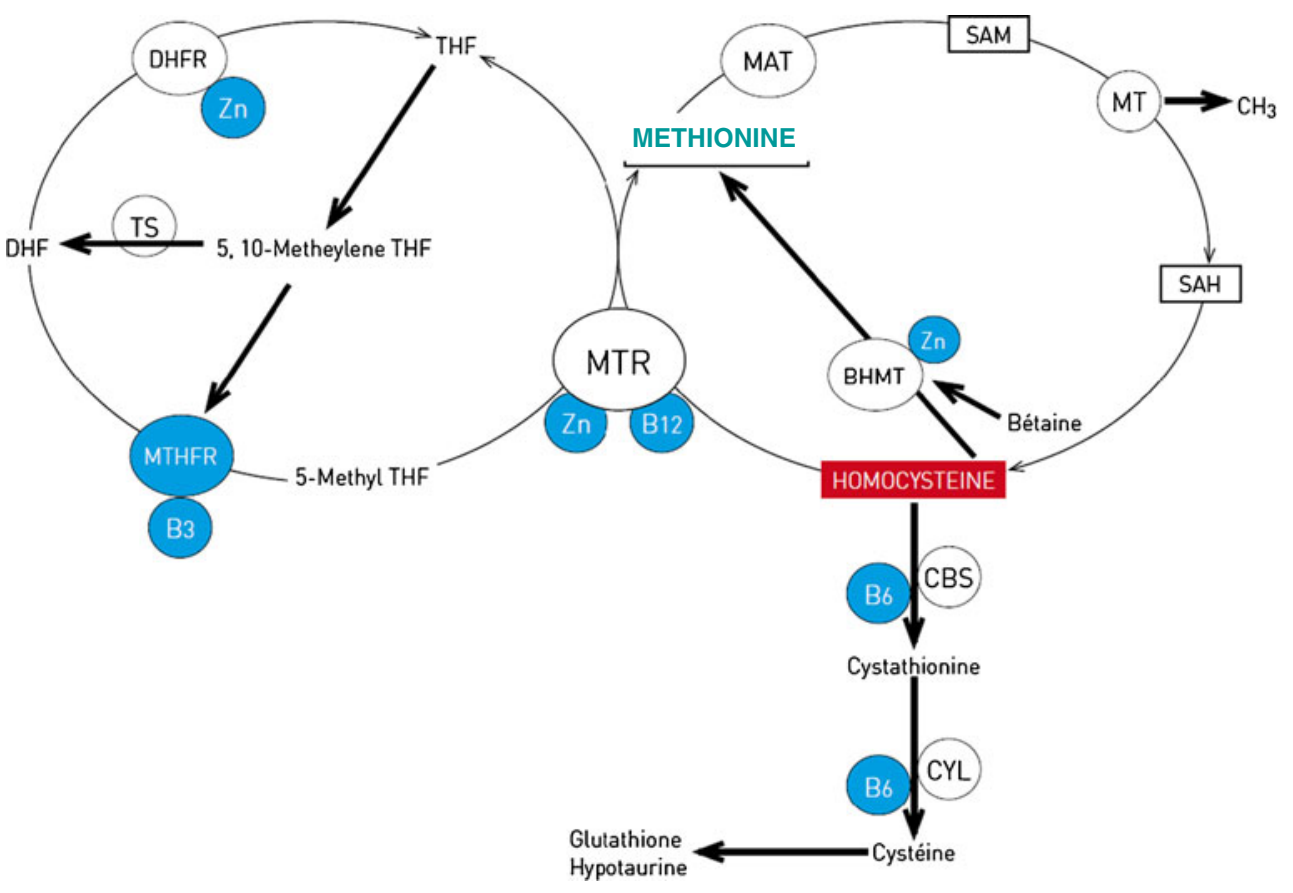


other words, the early human embryo has a very limited capacity to eliminate high homocysteine levels in the environment, in particular after controlled ovarian hyperstimulation $(12,13)$. The embryo has very little protection against free radicals during its preimplantation journey, especially under in vitro conditions. Free radical adducts induce alterations in DNA cytosine methylation (14) and we have demonstrated the presence of DNA adducts in gametes and early embryos (15). Smallwood et al. (16) suggest that maintaining methylation pathways is crucial for preimplantation embryos: "it is a decisive factor in imprinting". Kattari et al. (2) further suggest that abnormal methylation affects both imprinted and non-imprinted gene expression equally. In IVF, maternal age may be another limiting factor for the recycling of homocysteine, as the quality and the quantity of mRNA present in the oocyte decrease with age. In the American Nurses' Health II study, the autism risk was less pronounced among the infants of younger mothers who took fertility drugs

Taken together, these observations suggest that parameters linked to homocysteine metabolism should be monitored immediately before and during pregnancy, both in the mother and during early infancy of the child. This could allow diseases related to methylation failure to be detected, and the risks limited. Folic acid supplementation, as often proposed (17), is one piece of the solution, but the other B vitamins and Zinc should also be monitored. In infant monkeys (18), marginal zinc deprivation affects behaviour (lethargy, apathy, and hypoactivity). According to the FDA, $15 \%$ of the North American population suffers from $\mathrm{Zn}$ deficiency (19). It is interesting to note that the onset of autism appears after the first year of life, probably during the period when the nervous system is undergoing stages of maturation and development. Very early detection of Hcy metabolic problems and supplementation with these essential factors could be a positive step towards preventing autism spectrum disorders, and this is a strategy that might be considered in pediatric preventive medicine. Supplementation in older autistic children may help to re-establish a correct metabolic profile (20), but the development of the nervous system is already established and the brain is not able to reverse the damaging processes and recover.

\section{References}

1. Amor DJ, Halliday J. A review of known imprinting syndromes and their association with assisted reproduction technologies. Hum Reprod. 2008;23:2826-34.

2. Katari S, Turan N, Bibikova M, Erinle O, Chalian R, Foster M, et al. Sapienza C DNA methylation and gene expression differences in children conceived in vitro or in vivo. Hum Mol Genet. 2009;18:3769-78.

3. Menezo Y, Elder K, Benkhalifa M. Dale B DNA methylation and gene expression in IVF. Reprod Biomed Online. 2010;20:709-10.

4. James SJ, Cutler P, Melnyk S, Jernigan S, Janak L, Gaylor DW, et al. Metabolic biomarkers of increased oxidative stress and impaired methylation capacity in children with autism. Am J Clin Nutr. 2004;80:1611-7.

5. Chauhan A, Chauhan V. Oxidative stress in autism. Pathophysiology. 2006;13:171-81.

6. James SJ, Melnyk S, Jernigan S, Cleves MA, Halsted CH, Wong $\mathrm{DH}$, et al. Metabolic endophenotype and related genotypes are associated with oxidative stress in children with autism. Am J Med Genet B Neuropsychiatr Genet. 2006;141:947-56.

7. Geier DA, Geier MR. A clinical and laboratory evaluation of methionine cycle-transsulfuration and androgen pathway markers in children with autistic disorders. Horm Res. 2006;66:182-8.

8. Paşca SP, Dronca E, Kaucsár T, Craciun EC, Endreffy E, Ferencz $\mathrm{BK}$, et al. One carbon metabolism disturbances and the C677T MTHFR gene polymorphism in children with autism spectrum disorders. J Cell Mol Med. 2009;13:4229-38.

9. James SJ, Melnyk S, Jernigan S, Hubanks A, Rose S, Gaylor DW. Abnormal Transmethylation/transsulfuration Metabolism and DNA Hypomethylation Among Parents of Children with Autism. J Autism Dev Disord. 2008;38:1966-75.

10. James SJ, Melnyk S, Jernigan S, Pavliv O, Trusty T, Lehman S, et al. A functional polymorphism in the reduced folate carrier gene and DNA hypomethylation in mothers of children with autism. Am J Med Genet B Neuropsychiatr Genet. 2010;153:1209-20.

11. Menezo Y, Khatchadourian C, Gharib A, Hamidi J, Greenland T, Sarda N. Regulation of S-adenosyl methionine synthesis in the mouse embryo. Life Sci. 1989;44:1601-9.

12. Benkhalifa M, Montjean D, Cohen-Bacrie P, Ménézo Y. Imprinting: RNA expression for homocysteine recycling in the human oocyte. Fertil Steril. 2010;93:1585-90.

13. Boxmeer JC, Steegers-Theunissen RP, Lindemans J, Wildhagen MF, Martini E, Steegers EA, et al. Homocysteine metabolism in the pre-ovulatory follicle during ovarian stimulation. Hum Reprod. 2008;23:2570-6.

14. Turk PW, Laayoun A, Smith SS. Weitzman SA DNA adduct 8hydroxyl-2'-deoxyguanosine (8-hydroxyguanine) affects function of human DNA methyltransferase. Carcinogenesis. 1995;16:12535.

15. Badouard C, Ménézo Y, Panteix G, Ravanat JL, Douki T, Cadet J, et al. Determination of new types of DNA lesions in human sperm. Zygote. 2008;16:9-13.

16. Smallwood SA, Tomizawa S, Krueger F, Ruf N, Carli N, Segonds-Pichon A, et al. Dynamic $\mathrm{CpG}$ island methylation landscape in oocytes and preimplantation embryos. Nat Genet. 2011;43:811-4.

17. Rogers EJ. Has enhanced folate status during pregnancy altered natural selection and possibly Autism prevalence? A closer look at a possible link. Med Hypotheses. 2008;71:406-10.

18. Golub MS, Gershwin ME, Hurley LS, Hendrickx AG, Saito WY. Studies of marginal zinc deprivation in rhesus monkeys: infant behavior. Am J Clin Nutr. 1985;42(6):1229-39.

19. Center for disease control and prevention (CDC) National center for Health Statistics (NCHS) National Health and Nutrition examination. Survey questionnaire Hyattsville MD 2001-2002

20. James SJ, Melnyk S, Fuchs G, Reid T, Jernigan S, Pavliv O, et al. Efficacy of methylcobalamin and folinic acid treatment on glutathione redox status in children with autism. Am J Clin Nutr. 2009;89:425-30. 